\title{
Escolas entre imigrantes poloneses no Rio Grande do Sul e a Nacionalização do Ensino
}

\author{
Schools among polish immigrants in Rio Grande do Sul and the \\ Nationalization of Education
}

\author{
Adriano Malikoski* \\ Universidade de Caxias do Sul \\ Lúcio Kreutz** \\ Universidade de Caxias do Sul
}

Resumo O presente texto tem por objetivo apresentar resultados de pesquisa sobre as escolas étnicas dos imigrantes poloneses no Rio Grande do Sul, de 1890 até a Nacionalização da Educação em 1938. Até 1938 havia 106 escolas étnicas polonesas em funcionamento nesse estado, das quais muitas possuíam ensino bilíngue em português e polonês. $\mathrm{O}$ material didático utilizado era em língua polonesa e portuguesa, com destaque para textos que retratavam a cultura polonesa e sua adaptação ao contexto dos núcleos coloniais. A História Cultural, como leitura do objeto de pesquisa, tem como metodologia uma abordagem reflexiva-analítica de diferentes fontes, tais como documentos, bibliografia e a História Oral em suas tramas na construção de uma narrativa.

PALAVRAS-CHAVE: Imigração polonesa; Escolas étnicas polonesas;

Nacionalização do Ensino.

\begin{abstract}
This paper aims to present results of research on ethnic schools of Polish immigrants in Rio Grande do Sul,Brazil, from 1890 to the Nationalization of Education in 1938. Before 1938, there were 106 (one hundred-six) Polish ethnic schools operating in this state, many of which had education bilingual in Portuguese and Polish. The courseware was used in Polish and Portuguese, with emphasis on texts that portrayed the Polish culture and its adaptation to the context of colonial settlements. A Cultural History, as a reading of the research object, has a reflexive methodology one analytical approach from different sources, such as documents, literature and oral history in his plots to build a narrative.
\end{abstract}

KEYWORDS: Polish immigration; Polish ethnic schools; Nationalization of Education. 


\section{Introdução}

O processo escolar entre os imigrantes poloneses no Rio Grande do Sul foi organizado a partir das características típicas da cultura polonesa trazidas com os imigrantes e suas relações com o contexto de formação dos núcleos coloniais do Rio Grande do Sul. Segundo o censo escolar da imigração polonesa no Brasil, realizado pelo Consulado da Polônia de Curitiba, em 1938, no Rio Grande do Sul havia 106 escolas étnicas polonesas em funcionamento. Nesse sentido, nosso objetivo é trazer conclusões parciais de como se constituíram as escolas étnicas entre os imigrantes poloneses até a nacionalização do ensino em 1938 e compreender como a organização dos núcleos coloniais influenciou na formação desse sistema.

A Nacionalização do Ensino foi um processo de intervenção do estado nos rumos da educação no Brasil, em que a escola e seu planejamento passam a ser assumidos como um problema de governo, com o objetivo de reformar e nacionalizar a infância. Marcou intensamente o processo de escolarização, principalmente na região Sul do Brasil, através da fiscalização e acompanhamento dos processos de ensino entre as comunidades étnicas.

A História Cultural, como leitura desse processo, privilegia a compreensão dos muitos aspectos que envolvem a reconstrução do passado, no cuidado e no tratamento das fontes e na leitura das tramas estabelecidas no conjunto das representações da dimensão do simbólico e não apenas na interpretação unilateral de documentos oficiais na construção de uma narrativa. Segundo Pesavento (2008), a incorporação dessa dimensão simbólica das formas de organização pela qual os homens elaboram uma maneira particular de representar o mundo, tanto na linguagem como nas imagens possíveis do real, dizem muito mais do que a materialização dos documentos e dos registros.

Neste artigo, a História Oral foi preponderante na busca de sentidos sobre as escolas, através de entrevistas com ex-alunos, descendentes de imigrantes poloneses. Nas falas dos entrevistados pudemos desvelar alguns indícios recorrentes sobre o processo de ensino étnico polaco no Rio Grande do Sul, os quais consideramos importantes para a construção desta narrativa. Cada entrevista, cada memória contada e ouvida formaram sentidos e significados para a reconstrução do passado sobre as escolas étnicas polonesas na complementação das fontes materiais.

Para a análise da formação dos núcleos étnicos poloneses e suas comunidades, bem como para o entendimento do processo escolar, serão fundamentais alguns autores, como Barth (1998), Hall (2006), Hannerz (1997) e Kreutz (2003) que trazem importantes discussões a respeito da formação de grupos sociais.

A delimitação espacial restringe-se à análise das escolas étnicas polonesas no Rio Grande do Sul, porque é um assunto inédito em relação ao Estado e também pela disponibilidade de fontes de pesquisa. Dentre as disponíveis estão documentos e relatórios do consulado da Polônia em Curitiba, relações de registros de alunos, livros caixa de escolas, boletins escolares, correspondências oficiais de associações de professores e documentos oficiais de relação de professores, que são fontes relacionadas com o processo de ensino da etnia polonesa. 
As fontes são produções culturais humanas, elaboradas por ou para uma instituição, com um propósito específico. Pesquisar numa perspectiva cultural requer a compreensão de seus múltiplos aspectos, necessitando diferentes níveis de aprofundamento de acordo com os objetivos buscados. Acreditamos que uma narrativa é elaborada através da interação com as fontes, postulando um caráter processual da ciência, entendendo que o conhecimento é contingente, sendo ele possível até onde os instrumentos disponíveis do método podem alcançar.

A maioria dos imigrantes poloneses trouxe documentos expedidos pela Rússia, Prússia e Áustria, países que na época das emigrações dividiam o território polonês. No Brasil, devido à nacionalidade ser definida pela condição geopolítica dos territórios de origem dos indivíduos, os imigrantes poloneses eram elencados, comumente, como russos, alemães ou austríacos nas estatísticas ou na documentação oficial. Nesse sentido, buscamos no conceito de etnicidade a designação dos imigrantes poloneses e a localização de seus núcleos. Ou seja, a etnicidade como aporte da cultura e das transformações dos processos identitários que formaram uma conjunção de solidariedade, propiciando o surgimento de comunidades e, posteriormente, um sistema de ensino.

O entendimento de que os processos identitários são importantes para explicar as influências e as transformações de fluxos culturais, a transformação das produções humanas se faz necessária. Nessa perspectiva, buscamos descrever o processo de formação dos núcleos coloniais na chegada dos imigrantes e na formação de suas comunidades a partir da etnicidade.

\section{Processo étnico-comunitário e a escola}

O primeiro núcleo de imigrantes etnicamente polacos no Rio Grande do Sul foi formado por 26 famílias em 1875, vindos da Silésia, naquele momento sob dominação da Prússia. Teriam chegado juntamente com os imigrantes franco-suíços que se estabeleceram na colônia Conde D’Eu, entre os municípios de Garibaldi e Carlos Barbosa. Contudo, há autores como Kozowski (2003) e Gardolinski (1958) que consideram a vinda de imigrantes poloneses, em anos anteriores, dispersos na imigração alemã. Entretanto segundo, Gluchowski (2005), os maiores contingentes de imigrantes poloneses chegaram ao Rio Grande do Sul entre os anos de 1886 e 1894 e entre 1908 e 1912, formando diversas comunidades e núcleos em todo o Estado.

Em comparação com outros grupos, como os italianos e alemães, os poloneses podem ser considerado minoria. Porém, tiveram suas especificidades em relação à cultura e à sua inserção nos núcleos coloniais, que estão presentes ainda hoje em muitas cidades do Rio Grande do Sul.

A vinda dos primeiros grupos de imigrantes poloneses, em relação ao regime político brasileiro, e a instalação dos primeiros núcleos coloniais foram organizadas ainda no governo imperial. A criação da colônia Conde D'Eu em área cedida pelo governo imperial - nas encostas da serra gaúcha em 1870 pelo Ato de 24 de maio, do presidente da Província do Rio Grande do Sul, João Sertório - irá formar, em 1875, o primeiro núcleo de imigrantes poloneses instalados no Rio Grande do Sul. 
Até 1886, além do núcleo da linha Azevedo Castro na colônia Conde D’Eu, formaram-se dois núcleos em Santa Bárbara e Santa Tereza na colônia Dona Isabel, aos arredores do que é hoje o município de Bento Gonçalves. De acordo com Kozowski (2003, p. 13), os núcleos da Linha Azevedo Castro, Linha José Julio e Terceira seção do Rio das Antas foram os pioneiros da imigração polonesa na Serra Gaúcha, todos localizados em colônias notadamente constituídas por imigrantes italianos.

Depoimentos de descendentes e de autores como Gardolinski (1958), Stawinski (1999), e a partir de documentos da Companhia de Terras e Colonização, ligados ao Ministério da Agricultura e o Comércio e Obras Públicas, levam a crer que esses foram os três primeiros núcleos que formaram as primeiras comunidades étnicas polonesas homogêneas no Rio Grande do Sul. Consta desse período, em 1877, a presença de um pequeno grupo de imigrantes poloneses que se estabeleceram também na Colônia Caxias na $9^{\circ}$ légua.

Conforme relatório apresentado à Assembleia Geral Legislativa de Rio de Janeiro, através do Ministro e Secretário dos Negócios da Agricultura e Comércio e Obras Públicas João Lins Vieira Casansão de Sinimbu, em 27 de dezembro de 1878, há registros de que na colônia Campo dos Bugres (Caxias) haviam se estabelecido dentre 2315 italianos, 1007 tiroleses, 206 brasileiros, 202 alemães - 49 polacos, além de um pequeno número de franceses, espanhóis, suíços e ingleses.

Grupos como o referido pelo documento, não necessariamente formaram comunidades étnicas com escolas e sociedades. Nos primeiros anos que chegaram os imigrantes poloneses, era comum migrações para onde havia comunidades étnicas mais homogêneas no Rio Grande do Sul.

Com a ocupação total dos lotes da colônia Conde D’Eu e D. Isabel, os imigrantes poloneses começam a ser encaminhados a outros núcleos coloniais. Após a fundação da Colônia Alfredo Chaves, o Relatório de Francisco de Barros e Accioli de Vasconcelos de 1887, que na época era inspetor Geral da Inspetoria Geral de Terras e Colonização, cita na página 22, a presença de imigrantes "polacos", dentre os 1564 imigrantes que teriam chegado um ano antes da apresentação do referido relatório, inaugurando a colônia de Alfredo Chaves.

Gardolinski (1958) informa que a imigração em maiores contingentes para essa colônia, desenvolve-se, consideravelmente, após 1890, coincidindo com a ampliação da vinda de imigrantes. Segundo o autor, é desse período também a formação de novos assentamentos e núcleos de imigrantes poloneses também em outras regiões do Estado do Rio Grande do Sul, como na Colônia São Feliciano, Ijuí, Porto Alegre, Mariana Pimentel e Rio Grande.

Entre os imigrantes poloneses, o primeiro impulso para a formação de comunidades esteve relacionado à identidade e à cultura étnica. Em relação à formação étnica comunitária, os Freis Capuchinhos D’Apremont e Gillonnay, em relatório referente aos anos de 1896 até 1915, assim se referem: "os imigrantes poloneses, permanecem agrupados e muito fiéis à sua língua e à mãe-pátria, sem, contudo, deixarem de cumprir seus deveres com referência à pátria adotiva." (D'APREMONT E GILLONNAY, 1976, p. 44). 
Essa relação entre língua e etnicidade colaborou para a formação das primeiras comunidades, influenciadas pela forma como os imigrantes poloneses foram assentados. Como atesta o relatório do Ministério da Agricultura e Obras Públicas de 1876, as comissões de terras organizavam a demarcação dos lotes, seguindo geralmente a organização em linhas, travessões ou secções, conforme a topografia dos terrenos das colônias fundadas. Tudo era processado de acordo com o significado que a comunidade possuía para a formação dos grupos.

Além da relação étnica, aliada às condições de assentamento dos colonos, outro impulso importante de formação das primeiras comunidades estava ligado à religiosidade. Como descrevem D'Apremont e Gillonnay (1976), os primeiros tempos da formação dos núcleos poloneses eram caracterizados por uma situação de abandono, em que os imigrantes poloneses não possuíam atendimento religioso por parte de sacerdotes católicos ou de qualquer acompanhamento oficial dos países de onde provinham. Em que pese o forte apreço religioso que os imigrantes possuíam, esse atendimento nas diversas colônias só iria se estabelecer, de forma ainda precária, em meados do século XIX e início do século XX, quando se inicia a vinda dos primeiros sacerdotes católicos poloneses para prestar assistência religiosa a esses imigrantes.

Um dos primeiros sacerdotes a atender as comunidades polonesas foi o Padre Jesuíta José Von Lassberg, que era um missionário itinerante que atendia as comunidades polonesas no Rio Grande do Sul e em outros estados. Em carta enviada em setembro de 1902 a seu irmão na Baviera, o padre Jesuíta narra sua estada na Colônia de Dom Feliciano, que traz o sentido da importância dada à religiosidade pelos imigrantes poloneses. Consta que, em sua chegada, os imigrantes o receberam com hospitalidade, pois já havia muito tempo que esperavam pela chegada de um missionário.

De acordo com Gardolinski (1972), a referida colônia, no dia 15 de novembro de 1891, ano da vinda dos primeiros imigrantes poloneses, tinha registros referentes a um padre franciscano de nome Marcin Modrzejewski que anotou os primeiros batizados e casamentos na capela edificada junto com uma casa paroquial. Com a partida desse padre para os Estados Unidos, a colônia recebeu um novo sacerdote somente em 1896, sendo atendida nesse meio tempo pelos sacerdotes itinerantes. Segundo Stawinski e Busatta (1982), um desses sacerdotes era o padre Italiano Josué Bardin, que aprendeu a língua polonesa, passando a atender todas as comunidades onde existiam imigrantes dessa etnia em diversas localidades.

Contudo, para organização das comunidades e do processo de ensino entre os imigrantes poloneses desenvolveu papel decisivo a formação e a fundação de sociedades. Essas iniciativas deram um importante impulso na constituição de um processo de ensino étnico entre os imigrantes poloneses. Gluchowski (2005), em relatório de 1922 , refere, entretanto, que a fundação da primeira sociedade aconteceria somente no dia 15 de junho de 1890 em Curitiba. De acordo com a ata de fundação dessa sociedade, os imigrantes poloneses que se encontravam nas colônias não possuíam sociedades nem bibliotecas populares. Estavam isolados do mundo civilizado, com alusão à decadência moral, física e econômica. 
No Rio Grande do Sul, de acordo com o almanaque Kalendarz Polski de 1898, a iniciativa de fundação das primeiras sociedades coube ao viajante polonês Estanislau Klobukowski, delegado da Sociedade Geográfico-Comercial de Lwów de domínio da Áustria. Seu objetivo era acompanhar o processo de imigração polonesa para a América do Sul, ao mesmo tempo em que visitava as colônias e estimulava a formação de sociedades. A primeira delas de etnia polonesa foi fundada no dia 13 de maio de 1896, na colônia Jaguari, no centro do Estado. O nome da sociedade era Bartosz Glowacki, possuindo 41 sócios fundadores.

Em Ijuí, no dia 17 de maio de 1896, foi fundada a Sociedade Tadeusz Kosciuszko, em meio a uma colônia que congregava aproximadamente 500 famílias polonesas e 25 lituanas, tendo como presidente o Padre Antoni Cuber, considerado um dos líderes da colonização da região das missões por imigrantes poloneses. Em Porto Alegre no dia 01 de junho 1896 foi fundada a sociedade Zgoda (concórdia) tendo como dirigente Feliks Zdanowski, que mais tarde se tornará professor e editor de periódicos.

A fundação de sociedades, em seus estatutos, em grande parte objetivava a organização da educação entre os imigrantes poloneses. Essa iniciativa estimulou, posteriormente, a formação de um processo de ensino entre as comunidades étnicas polonesas, tanto no Rio Grande do Sul como em outros estados do país. Segundo Gluchowski (2005), havia a necessidade de se concentrar e de defender os interesses étnicos em relação ao ensino e à comunidade.

Com o passar do tempo, muitas sociedades surgiram com finalidades diversas, como a Sociedade de Ex-combatentes e a de Ajuda Humanitária para as vítimas da Guerra na Polônia, além de sociedades ideológicas progressistas, como a Sociedade de Livre Pensamento, fundada na década de 1920 em Porto Alegre. Ao fim de 1937, de acordo com os relatórios do consulado polonês em Curitiba, existiam 128 sociedades voltadas exclusivamente para o ensino particular étnico no Rio Grande do Sul.

\section{Imigração e Escolas étnicas polonesas no Rio Grande do Sul}

Para entender esse processo, é necessário explicitar algumas informações sobre a vinda de imigrantes poloneses para o Rio Grande do Sul. Kula (1996) explicita três motivos que atraiam os emigrantes poloneses para o Brasil. O primeiro motivo foi a possibilidade de posse de terras. O segundo foi a possibilidade de liberdade social em confrontação com as restrições impostas pelos países ocupantes do território polonês em relação à língua e à religião, além das relações agrárias presentes nos territórios dominados. Um terceiro motivo teria sido as representações de democratismo, supostamente existente em terras brasileiras, onde o emigrante poderia viver com mais dignidade, sem ser subjugado.

Desde 1795, o território polonês estava dividido entre Prússia, Rússia e Áustria. Cada nação dominante tratava de forma diversa a realidade escolar para os poloneses, no momento das emigrações. A partir da revolta armada de $1863^{1}$, em que os poloneses foram sufocados pelas tropas russas, houve a proibição de escolas, da língua e, além de perseguições religiosas nos territórios dominados pela Rússia. 
A Prússia, por sua vez, não proibiu as escolas, mas a língua a ser utilizada devia ser o alemão, num processo de germanização dos poloneses. Em relação à dominação da Áustria, os poloneses detinham mais liberdade em seus processos étnicos, porém, a conjuntura de miséria e as tensões agrárias privavam milhares de crianças do acesso às escolas. Essa é uma informação importante, porque especifica o motivo de grande parte desses imigrantes terem vindo com o mínimo de ensino, principalmente, das regiões ocupadas pela Rússia e pela Áustria.

Entre 1885 e 1947, Gardolinski (1958, p. 6.) pontua que, para o Rio Grande do Sul, vieram aproximadamente 23796 imigrantes poloneses. Entretanto, esse número pode ter sido maior, porque, segundo o autor, existem poucos elementos que caracterizem, por exemplo, a cultura russa ou austríaca no Estado. No Relatório da Repartição e Estatísticas do Estado do Rio Grande do Sul de 1920 há indícios de que grande parte do número de imigrantes dessas nacionalidades possa ser de imigrantes poloneses.

De acordo com Gardolinski (1958) e Gluchowski (2005), podemos situar a colonização dos imigrantes poloneses em 4 regiões distintas, onde se estabeleceram os núcleos coloniais mais homogêneos e, posteriormente, formaram-se comunidades e escolas. Certamente, houve outras localidades menores que também receberam imigrantes poloneses, porém trata-se de indivíduos em número reduzido ou que não formaram necessariamente comunidades com escolas étnicas.

A primeira Região a receber imigrantes poloneses localiza-se próximo ao litoral do Rio Grande do Sul nos seguintes municípios: Rio Grande, Pelotas, Santo Antônio da Patrulha, Dom Feliciano, Mariana Pimentel, Camaquã, Barão do Triunfo e Porto Alegre.

A segunda região localiza-se na Serra Gaúcha nos municípios de São Marcos, Antônio Prado, Veranópolis, Santa Tereza, Santa Barbara, Bento Gonçalves, Guaporé, Casca, Nova Prata, Nova Roma do Sul, Vista Alegre do Prata e arredores.

A terceira região, constituída também por indivíduos que migraram da região da serra, acha-se no Planalto Norte e no Vale do Uruguai, com os municípios de Erechim, Getúlio Vargas, Gaurama, Carlos Gomes (Nova Polônia), Dourado, Balisa, Marcelino Ramos, Áurea, Lajeado Valeriano, Barão do Cotegipe, Aratiba, Capoeré dentre outras localidades menores.

O quarto núcleo de imigrantes poloneses situa-se na Região das Missões nos municípios de Santo Ângelo, Ijuí, Santa Rosa, Guarani das Missões, Três de Maio, Tucunduva e arredores.

Os primeiros espaços de ensino, conforme depoimentos de descendentes, foram casas de alguns colonos. $\mathrm{O}$ professor era escolhido dentre aqueles que possuíam alguma instrução ou domínio de certo conhecimento em relação às primeiras letras ou cálculos. Em alguns núcleos, no início das comunidades, após a construção da igreja e a formação da sociedade, buscavam também edificar uma escola. 
Segundo dados do almanaque Kalendarz Polski, de 1898, pressupõe-se que uma das primeiras escolas, propriamente dita, da imigração polonesa no Rio Grande do Sul foi criada em 1897, mantida pela Sociedade Zgoda em Porto Alegre. O espaço de reuniões da sociedade servia também de escola. Ao longo do tempo, diversas sociedades foram sendo formadas com suas respectivas escolas.

Podemos, ainda, distinguir dois tipos de organização escolar étnica polaca. No caso especial deste artigo, denominaremos escolas étnico-comunitárias e escolas étnicas particulares de instituições religiosas.

Nas escolas étnico-comunitárias, após a formação da sociedade, as comunidades construíam as escolas ou ofereciam determinado espaço para o ensino. Responsabilizavam-se pela compra de mobiliário e material didático e, ainda, pelo pagamento dos professores. As escolas étnicas particulares de instituições religiosas eram construídas por congregações que cobravam mensalidade dos alunos, sendo mantidas e administradas por irmãs religiosas ou sacerdotes católicos. Incluídas nessa perspectiva estão algumas escolas paroquiais e escolas de congregações religiosas.

Inicialmente, as primeiras escolas ensinavam somente em língua polonesa. Mais tarde, começaram a ensinar também em língua vernácula com a finalidade de integrar as crianças à cultura nacional brasileira, bem como para receber subvenções dos municípios, os quais exigiam que as aulas fossem dadas em língua portuguesa.

Nos Relatórios da Intendência Municipal da Antiga Colônia de Alfredo Chaves, apresentado pelo intendente Coronel Achylles Taurino de Rezende, nos anos 1910, 1911 e 1912, temos a relação de professores subvencionados pela municipalidade na ordem de $50 \$ 000$ reis mensais, destacando a participação do poder público na manutenção nas escolas.

Renk (2009) explica que as subvenções faziam parte do interesse do Governo Estadual em exigir que as escolas étnicas ministrassem aulas em Português, no sentido de nacionalizar a infância e os processos escolares. A situação precária das escolas e o baixo salário dos professores faziam das subvenções um auxílio importante para a manutenção de algumas escolas.

Com a declaração da Polônia como Estado Político independente na Europa a partir de 1918, as colônias polonesas começaram a receber também acompanhamento direto do Estado polonês, que enviava professores, educadores e livros didáticos. Stawinski (1977) pontua que essas medidas introduziram sensíveis melhoras na qualidade e desempenho do sistema de ensino das escolas étnico-comunitárias polonesas.

Segundo o relatório Przeglad Towarzystw i Szkol Polskich Brazylij (relatório das sociedades e escolas polono-brasileiras), realizado pelo Consulado da Polônia em Curitiba, em 1938, de modo geral, as fontes de manutenção das escolas no Rio Grande do Sul, em 1937, estavam assim constituídas: 59\% de participação direta dos colonos com mensalidades; 29\% eram subvenções municipais; o Governo Estadual participava com 7,5\%; e a CZP, Central de Professores ligada ao governo polonês após 1918 , com $12 \%$. 
Em fins de 1938, de acordo com o censo escolar realizado pelo Consulado da Polônia em Curitiba, havia no Rio Grande do Sul 128 escolas étnicas polonesas. Estudavam nessas escolas, 4560 alunos e lecionavam 114 professores. Nas referidas escolas, 117 tinham ensino bilíngue, português e polonês, $10 \mathrm{com}$ ensino em português e uma com ensino somente em polonês. Ainda em relação às escolas, 19 estavam fechadas temporariamente por falta de professores e $3 \mathrm{em}$ organização, perfazendo um total de 106 escolas em funcionamento. O número de escolas religiosas era de 7 e o número de escolas leigas era de 121.

Entretanto, com o Decreto-lei N ${ }^{\circ} 406$ de 4 de maio de 1938, Getulio Vargas proibiu ou inviabilizou o funcionamento de escolas étnicas no Brasil. $\mathrm{O}$ art. 85 ditava o seguinte:

Art. 85. Em todas as escolas rurais do país, o ensino de qualquer matéria será ministrado em português, sem prejuízo do eventual emprego do método direto no ensino das línguas vivas.

$\S 1^{\circ}$ As escolas a que se refere este artigo serão sempre regidas por brasileiros natos.

$\S 2^{\circ}$ Nelas não se ensinará idioma estrangeiro a menores de quatorze (14) anos.

$\S 3^{\circ}$ Os livros destinados ao ensino primário serão exclusivamente escritos em língua portuguesa.

$\S 4^{\circ}$ Nos programas do curso primário e secundário é obrigatório o ensino da história e da geografia do Brasil.

$\S 5^{\circ}$ Nas escolas para estrangeiros adultos serão ensinadas noções sobre as instituições políticas do país. (Doc. Cit. p. 10).

Os pontos decisivos para determinar o fim do processo de ensinos nas escolas étnicas polonesas no país foram os que faziam referência às restrições impostas para o uso e o ensino da língua estrangeira e, para algumas escolas, a obrigação de possuir professores brasileiros natos.

Constatamos que muitas escolas tiveram de fechar suas portas, porque o professor era imigrante ou vinha diretamente da Polônia para atuar no ensino e em sua organização. Em outras escolas, mantidas por associações, o objetivo era promover a cultura étnica polonesa pelo uso da língua, mas o Decreto de 1938 desestimulou a existência das mesmas.

Algumas escolas foram assumidas pelo poder público, principalmente as que estavam mais organizadas e que conseguiram adequar-se às novas resoluções. Muitos professores que ensinavam nessas escolas, após serem aprovados em concursos, puderam ser aproveitados e continuaram à frente das escolas assumidas pelo poder público. Porém, boa parte das escolas étnicas simplesmente fechou suas portas e jamais foi reaberta.

Havia escolas que até tentaram prosseguir com suas atividades, contudo, o novo Decreto-lei de agosto de 1939 ( $\mathrm{n}^{\circ} 1.545$ - de 25 de agosto de 1939) impôs 
restrições maiores ao uso da língua estrangeira em repartições públicas, em locais de aglomeração ou de reuniões civis, como igrejas e associações. Nessa perspectiva de restrições, as escolas, bem como diversas associações étnicas, que insistiam em funcionar, foram compulsoriamente fechadas.

No Rio Grande do Sul, embora, as maiores preocupações dos nacionalizadores fossem voltadas para as escolas étnicas alemãs e italianas, devido aos regimes políticos existentes na Alemanha e Itália, por extensão, o sistema de ensino étnico polonês sentiu as consequências das leis nacionalizadoras. Segundo o secretário da educação José Pereira Coelho de Souza (1941), em relação aos grupos de imigrantes poloneses, não havia grandes preocupações, porque não formavam grandes extensões de comunidades ou núcleos, como a imigração alemã e italiana no Estado.

Como pudemos constatar, em atas analisadas de sociedades da etnia polonesa, existem lapsos de escrita, com períodos bem definido entre o antes e o depois do decreto de 1938. Nas sociedades que continuaram funcionando, as anotações começam a ser escritas em língua portuguesa, enquanto outras foram escritas somente até o ano de 1938.

Apesar de Gertz (2014) afirmar que os imigrantes poloneses não apresentavam grandes preocupações, por serem supostamente vistos como "marginais sociais" e que causavam apenas "preocupações policiais" para os nacionalizadores, os efeitos desse processo também foram intensamente sentidos nas comunidades e nas organizações étnicas desse grupo de imigrantes. Segundo relatos dos próprios descendentes do grupo étnico polonês, as proibições das leis e dos decretos também aconteceram nos núcleos poloneses, havendo inclusive prisões.

Podemos atestar que a preocupação não estava simplesmente ligada à suposta condição de marginalidade, mas à condição política do Estado polonês que, após ser reconstituído em 1918, já no início da Segunda Guerra Mundial, é invadido novamente e ocupado pela Alemanha e União Soviética. Os regimes ultranacionalistas predominante na Itália e na Alemanha - como foram, respectivamente, o Fascismo e o Nazismo - e as ambições políticas imperialistas japonesas na Ásia despertavam maiores preocupações brasileiras com duras consequências para essas comunidades étnicas no Rio Grande do Sul.

\section{Considerações finais}

Muitas colônias receberam significativo número de imigrantes poloneses, os quais, seguindo a dinâmica da divisão dos lotes, fundaram suas comunidades, associações e, posteriormente, escolas.

A formação de comunidades homogêneas permitiu o surgimento do processo de ensino entre os imigrantes e descendentes de poloneses, que, ao longo do tempo, constituiu-se em um conjunto cultural e de processo identitário étnico.

Quando é mencionado o processo de ensino entre os imigrantes poloneses e seus descendentes, as fontes referendam sempre a existência, principalmente nas comunidades rurais, deste conjunto: capela, sociedade e escola. 
Na maioria das colônias, nos primeiro anos da imigração para o Brasil, o principal símbolo de organização comunitária era a capela ou a pequena igrejinha onde se formavam espaços de convívio social, e que, com o tempo, também serviram de espaço de ensino.

O número de escolas não atingiu a totalidade da população étnica polonesa, porque faltavam recursos financeiros, material didático e professores. Essa situação se agravou com a política de Nacionalização do Ensino empreendida pelo Governo de Getúlio Vargas.

É pertinente considerar a situação de isolamento em que se encontravam os núcleos coloniais de imigração polonesa que não possuíam escolas oficiais do Estado brasileiro. Nesse sentido, os imigrantes e descendentes formaram iniciativas particulares para obterem algum tipo de instrução e ensino em escolas, de acordo com sua cultura e processo étnico.

O processo escolar entre os imigrantes e descendentes de poloneses teve algumas peculiaridades, tais como escolas bilíngues, que ensinavam em vernáculo durante a manhã e em polonês durante a tarde, e a utilização de material didático tanto em português como em polonês. Muitos livros em língua polonesa eram desenvolvidos e impressos na Polônia, nos Estados Unidos e em Curitiba, processo que também foi interrompido pelas leis da Nacionalização.

Com a formação da Polônia como Estado independente, após a Primeira Guerra Mundial, constatou-se uma sensível melhora e ampliação do sistema de ensino. Foram enviados livros didáticos e vieram professores que atuaram na organização e na ampliação do sistema de ensino. Nesse período, houve maior estímulo para a formação de associações culturais e organizativas e o fortalecimento das que já existiam.

No entanto, com a Nacionalização do Ensino, entre os imigrantes poloneses pudemos constatar que houve um aumento do analfabetismo. Escolas foram fechadas, proibidas e, em muitos casos, jamais foram reabertas, deixando um contingente bastante expressivo de crianças sem escolas. Poucas escolas foram devidamente substituídas ou assumidas pelo poder público. Uma das dificuldades era conseguir professores que dominassem a língua portuguesa para cumprir com as exigências do processo de nacionalização do ensino.

A participação direta do Estado era definida com subvenções e, também, pela legislação, que estimulou o uso do vernáculo e de noções da História e Geografia do Brasil nas escolas. Muitas delas, para cumprir a legislação nas décadas de 1920 e de 1930, adotavam o bilinguismo: pela manhã ensinavam em língua vernácula e à tarde em língua polonesa para manter a identidade étnica. Destacamos, nesse sentido, que as escolas étnicas dos imigrantes poloneses foram uma prática de tempo integral.

Para o grupo dos imigrantes poloneses, as escolas étnicas tiveram importantes significados. $\mathrm{O}$ fechamento das escolas gerou conflitos e paixões na ocasião da campanha de Nacionalização promovida pelo o Estado Novo de Getúlio Vargas, que decretou o fim do processo de ensino étnico no Brasil. 
As escolas da imigração polonesa marcaram uma importante fase da historiografia da Educação no Rio Grande do Sul até 1938, por meio de um ensino voltado para as características étnicas e culturais desses imigrantes. Essa experiência perdura na memória dos indivíduos que passaram por essa realidade escolar. Embora em um contexto diferente ao da época - em que as escolas étnicas polonesas eram proibidas ou absorvidas pela cultura dos países que dominavam os territórios de populações polonesas no século XIX - com o processo de nacionalização do ensino do Brasil em 1938, novamente o grupo étnico polonês foi destituído de suas escolas.

\section{Referências}

BARTH, F. Grupos étnicos e suas fronteiras (1976), In: POUTIGANT, P; STREIFF-FENART, J. Teorias da Etnicidade. São Paulo: UNESP, 1998. p. 185-228.

BRASIL. Decreto-lei ${ }^{\circ} .406$, de 04 de maio de 1938. Dispõe sobre a entrada de estrangeiros em território nacional. Coleção de Decretos de 1931 a 1945.

BRASIL. Decreto-lei no ${ }^{\circ}$. 1545, de 25 de agosto de 1939. Dispõe sobre a adaptação ao meio nacional dos brasileiros descendentes de estrangeiros. Coleção de Decretos de 1931 a 1945.

CARTA do Padre José de Lassberg, S. J. 1902 - Tradução feita por Artur Rabuske. Datilografado - NPH/UFRGS Acervo Gardolinski.

D'APREMONT, B.; GILLONNAY, B. Comunidades indígenas, brasileiras, polonesas e italianas no Rio Grande do Sul. Caxias - Porto Alegre: UCS/EST, 1976.

GARDOLINSKI, E. Escolas da Colonização Polonesa no Rio Grande do Sul. Porto Alegre: Escola Superior de Teologia São Lourenço de Brindes. Caxias do Sul: UCS, 1977. 1958.

Imigração e colonização polonesa no Rio Grande do Sul. Porto Alegre: Regional,

GERTZ, R. E. Etnias e Nacionalização no Sul do Brasil. In: QUADROS, C. Uma gota amarga: itinerários da nacionalização do ensino no Brasil. Santa Maria: UFSM, 2014.

GLUCHOWSKI, K. Os poloneses no Brasil. Porto Alegre: Rodycz \& Ordakowski, 2005.

HALL, S. A identidade cultural na pós-modernidade. Tradução: Tomaz Tadeu da Silva e Guacira Lopes Louro. 11. ed. Rio de Janeiro: DPeA, 2006.

HANNERZ, U. Fluxos, fronteiras, híbridos: palavras-chave da antropologia transnacional. In: Mana - Estudos de Antropologia Social, v. 3, n. 1, p. 7-39, Rio de Janeiro: PPGAS - Museu Nacional - UFRJ, 1997.

KOZOWSKI, V. I. Estes imigrantes entre outros: imigração polonesa na serra gaúcha. Bento Gonçalves: Kozowski, 2003.

KREUTZ, L. Diferenças étnicas e educação intercultural: a partir de que entendimento de etnicidade? Série Estudos - Periódico do Mestrado em Educação da UCDB. Campo Grande: UCDB, n.15, p. 81-92, jan e jun, 2003.

KULA, M. A emigração polonesa no Brasil vista pelos pesquisadores da Polônia. In: Brasil Polônia: Primeiro Simpósio Cultural. Varsóvia: CESLA, 1997. p. 15-29

PESAVENTO, S. J. História \& história cultural. 2. ed. Belo Horizonte: Autêntica, 2008.

PRZEGLAD TOWARZYSTW I SZKOL POLSKICH BRAZYLIJ. Realizado pelo Consulado da Polônia em Curitiba em 1938. 
RELATÓRIO apresentando à Assembleia Geral Legislativa de Rio de Janeiro, através do Ministro e Secretário dos Negócios da Agricultura e Comércio e Obras Públicas João Lins Vieira Casansão de Sinimbu, em 27 de dezembro de 1878.

RELATÓRIO de Francisco de Barros e Accioli de Vasconcelos de 1887, Inspetor Geral da Inspetoria Geral das Terras e Colonização.

RELATÓRIO da Repartição e Estatísticas do Estado do Rio Grande do Sul em 1920 - Instituto Histórico do Rio Grande do Sul.

RELATÓRIOS da Intendência Municipal da Antiga Colônia de Alfredo Chaves, apresentado pelo intendente Coronel Achylles Taurino de Rezende nos anos 1910, 1911 e 1912.

RELATÓRIO de 27/12/1878 apresentado à Assembleia Geral na segunda sessão da décima sétima legislatura, pelo ministro e secretário de Estado dos Negócios da Agricultura, Comércio e Obras Públicas João Lins Vieira Cansansão de Sinimbu. Rio de Janeiro: Imprensa Industrial, 1879.

RENK, V. E. Aprendi falar português na escola! O processo de nacionalização das escolas étnicas polonesas e ucranianas no Paraná. Curitiba: UFPR, 2009. 241f. Tese de Doutorado em Educação. Programa de Pós-Graduação em Educação, Universidade Federal do Paraná.

SOUZA, J. P. C. Denúncia: o nazismo nas escolas do Rio Grande do Sul. Porto Alegre: Globo, 1941.

STAWINSKI, A. V. Primórdios da imigração polonesa no Rio Grande do Sul (1875-1975). 2. ed. Porto Alegre: EST, 1999.

. Introdução. In: GARDOLINSKI, E. Escolas da colonização polonesa no Rio Grande do Sul. Porto Alegre: EST, Caxias do Sul: UCS, 1977.

STAWINSKI, A. V.; BUSATTA, F. F. Josué Bardin: história e religião das colônias polonesas. Porto Alegre: EST/UCS, 1982.

WACHOWICZ, R. C. As escolas da colonização polonesa no Brasil. In: Anais da comunidade Brasileiro-Polonesa. Curitiba: Champagnat, 1970. Documentos.

\section{Nota}

${ }^{1}$ Levante organizado em janeiro de 1863 , em luta desigual contra a ocupação Russa, teve por objetivo a libertação dos territórios ocupados. Esse levante foi sufocado pelas tropas do Czar Alexandre II, imperador da Rússia, com perseguições e massacres posteriores das populações polonesas, acirrando ainda mais a política o conflito étnico.

* Professor da Universidade de Caxias do Sul, Caxias do Sul, Rio Grande do Sul, Brasil.

** Professor doutor da Universidade de Caxias do Sul, Caxias do Sul, Rio Grande do Sul, Brasil.

\section{Correspondência}

Lucio Kreutz - Universidade de Caxias do Sul, Departamento de Educação. Rua Francisco Getúlio Vargas, n. 1130, Petrópolis, CEP: 95070-560 - Caxias do Sul, Rio Grande do Sul - Brasil.

E-mail: adriano.malikoski@hotmail.com-1kreutz@terra.com.br

Recebido em 15 de maio de 2015

Aprovado em 11 de agosto de 2015 
